JURNAL PENDIDIKAN USIA DINI

DOI: https://doi.org/10.21009/JPUD.121
DOI: https://doi.org/10.21009/JPUD.121 14

\title{
MODEL KELINCAHAN PADA SISWA TAMAN KANAK-KANAK
}

\author{
WIDIASTUTI ${ }^{1}$, IWAN RIDWAN ${ }^{2}$ \\ ${ }^{1}$ Universitas Negeri Jakarta \\ ${ }^{2}$ Pendidikan Anak Usia Dini Al Izhar \\ ${ }^{1}$ Email: widi_harun@yahoo.com
}

\begin{abstract}
ABSTRAK
The aim of this research was to create an agility learning model for pre-elementary school students. The approach of this study used research and development model of Borg and Gall. The result of the small group trial from the easiness aspect was 85,58\% and the attractiveness aspect was $86,35 \%$ which were very good. Meanwhile, the result of the big trial from the easiness aspect reached $86,41 \%$ and from the attractiveness aspect reached $86,35 \%$ which were also very good. The effectiveness of the model was confirmed effective to be used. The result of to was 14,92 and $t$ table was 1,697, therfore to > t-table or Ho was rejected. It can be concluded that the agility learning model in this study is effective to be applied on early age kids.
\end{abstract}

Key words: Physical Education, Agility, Preschool

\begin{abstract}
Abstrak, Penelitian ini bertujuan untuk menghasilkan model kelincahan bagi siswa Taman KanakKanak. Pendekatan penelitian pengembangan model kelincahan ini menggunakan model penelitian dan pengembangan (Research and Development) dari Borg dan Gall.Hasil uji coba kelompok kecil diperoleh hasil kriteria ditinjau aspek kemudahan model pembelajaran kelincahan diperoleh nilai 85,58\% dan dinyatakan baik sekali, sedangkan aspek kemenarikan diperoleh nilai 86,16\% dan dinyatakan baik sekali. Hasil uji coba kelompok besar diperoleh hasil kriteria ditinjau aspek kemudahan model pembelajaran kelincahan diperoleh nilai $86,41 \%$ dan dinyatakan baik sekali sedangkan ditinjau dari aspek kemenarikan diperoleh nilai $86,35 \%$ dan dinyatakan baik sekali. Keefektifan model yang dikembangkan, dinyatakan efektif untuk digunakan. Berdasarkan dari hasil perbandingan antara nilai tes awal dan tes akhir yang diberikan kepada siswa diperoleh hasil $\mathrm{t}_{0}$ sebesar 14,92 dan $\mathrm{t}_{\text {tabel }}$ 1,697. Dengan demikian, $\mathrm{t}_{0}=14,92>\mathrm{t}_{\text {tabel }}=1,697$ atau $\mathrm{H}_{0}$ ditolak. Hasil penelitian ini menunjukan bahwa model kelincahan yang peneliti kembangkan efektif untuk diterapkan pada anak usia dini.
\end{abstract}

Kata Kunci: Pendidikan Jasmani, Kelincahan, PAUD 
Model Kelincahan......

Widiastuti dan Iwan

\section{PENDAHULUAN}

Permasalahan

utama

Pendidikan Jasmani di Indonesia sampai sekarang ini adalah masih kurang efektifnya pengajaran

Pendidikan jasmani di sekolahsekolah. Terutama pada tingkat Pendidikan Anak Usia Dini (PAUD) penelitian yang dilakukan di di tingkat taman kanak-kanak menunjukan $43 \%$ guru PAUD rendah dalam memberikan pembelajaran gerak. (Siregar, 2011)

Materi kelincahan adalah salah satu standar kompetensi yang telah ditetapkan pada aspek gerak lokomotor dalam Pendidikan Jasmani yang diajarkan di Taman Kanak-kanak. Dalam memberikan materi kelincahan, hendaknya guru dapat memberikan materi yang mengembangkan gerakan kelincahan sehingga siswa mempunyai gerakan kelincahan yang sangat baik.

Pengamatan peneliti dilapangan, penguasaan gerakan kelincahan masih rendah dalam pembelajaran praktik gerakan kelincahan disebabkan oleh beberapa faktor, seperti siswa kurang fokus dalam memperhatikan dan melaksanakan praktek pembelajaran kelincahan, siswa kurang semangat dan tidak aktif saat praktik pembelajaran kelincahan, guru kurang kreatif dan inovatif pada saat praktek pembelajaran kelincahan. Guru kekurangan model-model pembelajaran kelincahan dengan pendekatan bermain yang tepat untuk meningkatkan kesegaran jasmani.

Bertitik tolak dari pendapat di atas, maka penulis sangat tertarik untuk mengadakan penelitian tentang Model Pembelajaran Kelincahan Pada Siswa Taman Kanak - Kanak.

Kegunaan penelitian ini adalah Memberikan suasana belajar yang baru bagi siswa sehingga merasakan kesenangan dan kenyamanan dalam proses belajar mengajar, dan bagi guru berguna sebagai masukan pada pengajar khususnya di Taman Kanak-Kanak dalam meningkatkan kemampuan gerakan kelincahan

Menurut Solso dkk (2007:11) ujuan model adalah menyediakan reprensentasi yang dapat dipahami tentang hasil observasi dan untuk membantu menyusun prediksi. Menurut Husdarta (2013:2) model 
pembelajaran mempunyai empat ciri khusus yang tidak (1). Rasional teoritis yang logis yang disusun oleh pendidik, (2) Tujuan pembelajaran yang akan dicapai, (3) Langkahlangkah mengajar yang diperlukan agar model pembelajaran dapat dilaksanakan dengan optimal, (4) Lingkungan belajar yang diperlukan agar tujuan pembelajaran dapat dicapai.

\section{Model pengembangan} diartikan sebagai proses desain konseptual dalam upaya peningkatan fungsi dari model yang telah ada sebelumnya, melalui penambahan komponen pembelajaran yang dianggap dapat meningkatkan kualitas pencapaian tujuan. Pengembangan disini artinya diarahkan pada suatu program yang telah atau sedang dilaksanakan menjadi program yang lebih baik. Pengembangan model baru disusun berdasarkan pengalaman pelaksanaan program yang baru dilaksanakan, kebutuhan individu atau kelompok, dan disesuaikan dengan perkembangan dan perubahan lingkungan belajar warga belajar.
Penelitian pengembangan yang akan peniliti teliti merupakan yaitu pembuatan suatu produk yang efektif, diawali dengan analisis kebutuhan, pengembangan produk, uji coba produk dan evaluasi dalam rangka memberikan kemudahan untuk mencapai tujuan pembelajaran kelincahan pada siswa Taman KakaKanak (TK), setiap model pembelajaran harus disesuaikan dengan konsep yang lebih cocok dan dapat dipadukan dengan model pembelajaran lain untuk meningkatkan hasil belajar siswa.

Menurut Rahayu (2013:17) Pembelajaran Pendidikan jasmani pada hakikatnya adalah proses pendidikan yang memanfaatkan aktifitas fisik untuk menghasilkan perubahan holistik dalam kualitas individu, baik dalam hal fisik, mental, serta emosional.

Menurut Husdarta (2013:21) Pendidikan jasmani meruapakan media untuk mendorong perkembangan keterampilan motorik, kemampuan fisik, pengetahuan, penalaran, penghayatan nilai ( sikapmental- emosional-spiritual-sosial), dan pembiasaan pola hidup sehat 
yang bermuara untuk merangsang pertumbuhan serta perkembangan yang seimbang. Dari beberapa teori mengenai Pendidikan Jasmani terlihat jelas bahwa ranah pendidikan jasmani tidak hanya mengenai psikomotor saja, lebih dari itu pendidikan jasmani melibat ranah afektif dan psikomotor.

Anak akan merasakan perasaannya dalam melakukan aktivitas gerak, dalam Pendidikan Jasmani akan meningkatnya suatu prestasi dalam kehidupan sehari-hari dan membentuk sosial terhadap masyarakat dan membentuk pertumbuhan badan dengan cara pola hidup sehat.

Tujuan yang ingin dicapai melalui pendidikan jasmani di Taman Kanak-Kanak pun mencakup pengembangan individu secara menyeluruh. Artinya, cakupan pendidikan jasmani tidak hanya terfokus pada aspek fisik saja, melainkan juga aspek mental, emosional, sosial dan spiritual.

Menurut Samsudin (2014: 251) Pendidikan jasmani yang terdapat di Taman Kanak-Kanak dapat dijelaskan sebagai berikut: 1)
Membuat peredaran darah menjadi lancar dan tubuh akan menjadi kuat dan sehat, 2) Memacu pertumbuhan tinggi dan berat badan 3) Mengembangkan aspek mental 4) Menanamkan nilai-nilai kejujuran, disiplin, menghargai, kerjasama, berbagi dan tanggung jawab, 5) Meningkatkan kesegaran jasmani 6) Meningkatkan pengetahuan tentang pendidikan jasmani.

Pendidikan jasmani sangatlah penting untuk tumbuh kembang siswa, akan tetapi tidak semua guru menyadari hal menyadari arti penting pendidikan jasmani, sehingga banyak yang melihatnya hanya sebelah mata. Hal ini terlihat dari gambaran negatif dilapangan tentang pendidikan jasmani, misalnya anak bermain sendiri dilapangan yang tidak di kontrol atau di arahkan oleh guru sehingga mutu pembelajaran menjadi rendah.

Dalam pertumbuhan anak usia dini (PAUD) sering dikaitkan dengan kata perkembangan sehingga ada istilah tumbuh kembang. Pertumbuhan dan perkembangan adalah dua hal yang berbeda. Menurut Ahmad Susanto (2014:20- 
21) dalam buku Perkembangan Anak Usia Dini mengatakan pertumbuhan adalah ukuran dan bentuk tubuh atau anggota tubuh sedangkan perkembangan adalah perubahan mental yang berlangsung secara bertahap dalam waktu tertentu, dari kemampuan yang sederhana menjadi kemampuan yang lebih sulit.

Keterampilan motorik atau psychomotor skill dapat diartikan sebagai eksekusi atau pelaksanaan suatu tindakan untuk mencapai hasil tertentu. Kemampuan motorik pada umumnya melibatkan aktivitas berupa tindakan yang bersifat fisik dan penggunaan otot untuk melakukan suatu tindakan yang bertujuan. Menurut James Tangkudung dan Wahyuningtyas (2012:67) Kondisi fisik yang baik akan mempengaruhi aspek-aspek kejiwaan yang berupa peningkatan motivasi kerja diantaranya: semangat kerja, rasa percaya diri, ketelitian, dan lain sebagainya. Pengembangan domain pembelajaran psikomotorik berfokus pada menjalankan kegiatan motorik hingga satu tingkat akurasi, kelancaran, kecepatan, atau kekuatan tertentu.
Dalam pembelajaran psikomotorik tidak menitikberatkan hanya penggunaan otot saja, tetapi keterampilan berpikir mempunyai peran juga. Seperti yang dikatakan oleh Khoe Yao Tung (2015:222) berpikir adalah memanipulasi dan mentransformasi informasi didalam memori yang sering dilakukan dalam bentuk meyusun konsep, menimbang alasan, berpikir kritis, membuat keputusan, berpikir kreatif, dan menyelesaikan masalah.Tindakan dalam keterampilan motorik dapat dilakukan baik dengan alat maupun tanpa alat. Tindakan yang terlihat dalam keterampilan motorik pada dasarnya tidak hanya berupa tindakan fisik semata, tapi juga melibatkan tindakan mental di dalamnya. Unsur mental menentukan bagaimana seseorang melakukan suatu tindakan dengan baik.

Perkembangan menyeluruh anak melalui pergerakan menurut Miang (2010:10) 1) Perkembangan Kognisi Latihan berbagai macam gerakan dapat mengembangkan berpikir kreatif dan pengambilan keputusan. Anak - anak yang secara fisik bugar cenderung lebih peka 
secara mental, 2) Perkembangan

Fisik Pembiasaan dalam melakukan aktivitas bergerak dan olahraga membangun kebugaran jasmani dan mendukung pertumbuhan fisik dan menjadi dasar untuk tubuh yang lebih kuat dan sehat, 3) Perkembangan Psikomotor Bermain dan bergerak dapat mengaktifkan sambungan otot saraf. Anak - anak yang memiliki kemampuan gerak dasar dapat berpartisipasi penuh di area olahraga dan aktivitas gerak, 4) Perkembangan Afeksi Anak yang terampil dalam melakukan gerak dasar dapat menilai diri mereka secara positif, mempengaruhi kemampuan, mereka percaya diri dan memiliki jiwa kepemimpinan.

Dari berbagai pendapat di atas dapat disimpulkan bahwa pembelajaran atau latihan merupakan bahwa konsistensi motorik meskipun semua keterampilan motorik unik, masih perlu belajar untuk bergerak dengan cara yang terampil. Artinya, meskipun kita tidak pernah menghasilkan suatu keterampilan dengan cara yang persis sama dalam dua kali. Keterampilan bisa timbul dengan cara berlatih dan menjadi baik, sangat konsisten dari satu waktu ke depan dalam mencapai hasil yang sama. Dalam pembelajaran atau latihan harus dilakukan berulang-ulang secara benar sehingga menjadi gerakan otomatisasi.

Kelincahan berkaitan erat dengan kecepatan dan kelentukan. Tanpa unsur keduanya, seseorang tidak dapat bergerak dengan lincah. Faktor keseimbangan juga sangat berpengaruh terhadap kemampuan agility seseorang. Kelincahan berkaitan dengan gerak tubuh yang melibatkan gerak kaki dan perubahan-perubahan yang cepat dari posisi badan. Dalam melakukan gerakan kelincahan tidak hanya mengandalkan kualitas fisik melainkan kemampuan kognitif perlu diperhatikan pula, Dewis dan Roozen (2012:1) mengatakan Agility can be broken down into sub components made up of both physical qualities and cognitive abilities. Menurut Widiastuti (2011:125) Agility atau kelincahan adalah kemampuan untuk mengubah arah atau posisi tubuh dengan cepat yang dilakukan bersama-sama dengan gerakan 
lainnya. agility is the ability to change initial direction to a predetermined location and space on the field of court is known as changeof-direction speed (CODS). ( Joyce dan Lewindon, 2014:185) Sedangkan menurut Gatz (2009:113) Agility is the ability to react to a situation swiftly while coordinating quick starts and stops under control make a play.

Menurut penjelasan diatas bahwa Kelincahan adalah Kemampuan seseorang dapat merubah arah secepat mungkin dengan keadaan posisi yang seimbang.

Ada beberapa faktor yang mempengaruhi agility menurut Mackenzie (2005:55) antara lain sebagai berikut :

1) Balance - Maintenance of the centre gravity over the base of support, it has a static and dynamic quality, 2) Kinaesthetic Diferenntation - Ability to feel tension in movement to achieve the desired movement, 3) Spatial Orientation - The control of the body in space, 4) Reaction to Signals The ability to respon quikly to auditory, visusal and kinaesthetic cues, 5) Sense of Rhythm - The abilityto match movement to time, 6) Synchronization of Movements in Time - Unrelated limb movements completed in a synchronised manner, 7) Movement Adequacy - Ability to choose movements appropriate to the task.

Dari penjelas tersebut dapat diartikan bahwa terdapat faktor yang mempengaruhi kelincahan yaitu Keseimbangan, kemampuan memposisikan tubuh, kemampuan mengontrol tubuh pada suatu tempat, kemampuan menerima stimulus, kemampuan untuk menyesuaikan gerakan. Tujuh faktor tersebut harus dilatih agar kelincahan seseorang menjadi lebih baik.

Selanjutnya menurut Lancaster dan Teodorescu (2008:144) : “Agility training prepares the body to react and become comfortable moving in the most effective and efficient ways possible in order to make crucial plays and improveoverall performance". Latihan kelincahan yaitu untuk mempersiapkan tubuh agar dapat bergerak secara efektif 
dan efisien dalam situasi bermain atau ketika pertandingan.

\section{METODE PENELITIAN}

Tujuan akhir dari penelitian dan pengembangan ini adalah menghasilkan produk berupa model pembelajaran kelincahan pada siswa Taman Kanak - Kanak sehingga lebih efektif, efisien dan menarik dalam pelaksanaan pembelajaran. Penelitian ini dilaksanakan di 5 Taman Kanak - Kanak Jakarta Selatan, (TK Hangtuah, TK Puri Ananda, TK Al Izhar, TK Al Azkar dan TK Azhari Global Islamic School Jakarta Selatan). Waktu yang dperlukan dalam penelitian dan pengembangan ini selama 3 bulan lebih dengan perincian waktu sebagai berikut: a) analisis kebutuhan, b) perencanaan pengembangan model, c) pengembangan desain model pembelajaran, d) Validasi pakar dan revisi model e) uji coba kecil dan revisi, f) uji coba lapangan dan revisi.

Sasaran penelitian atau pengguna yang akan diteliti dalam penelitian pengembangan model pembelajaran kelincahan adalah seluruh siswa kelas B yang berusia 5 -6 tahun (subyek homogen).

Pendekatan penelitian pengembangan model pembelajaran kelincahan ini menggunakan model penelitian dan pengembangan (Research and Development) dari Borg dan Gall (1983:775) yang terdiri dari sepuluh langkah antara lain:

(1). Melakukan penelitian dan pengumpulan informasi (kajian pustaka, pengamatan subyek, persiapan laporan pokok persoalan) (2) Melakukan perencanaan (pendefinisian keterampilan, perumusan tujuan, penentuan urutan pengajaran, dan uji coba skala kecil) (3) Mengembangkan bentuk produk awal (penyiapan materi pengajaran, penyusunan buku pegangan, dan perlengkapan evaluasi)

Melakukan uji lapangan permulaan (menggunakan 6-12 subyek) Melakukan revisi terhadap produk utama (sesuai dengan saran-saran dari hasil uji lapangan permulaan) (6) Melakukan uji lapangan utama (dengan 30-100 subyek). Melakukan revisi produk 
(berdasarkan saran-saran dan hasil uji coba lapangan utama). (8) Uji lapangan dengan 40-200 subyek (9) Revisi produk akhir (10) Membuat laporan mengenai produk pada jurnal, bekerja dengan penerbit yang dapat melakukan distribusi secara komersial.

Pada saat pengembangan yang dilaksanakan dengan uji coba, validasi, dan revisi produk. Penelitian dan pengembangan ini menggunakan metode pendekatan kuantitatif dan kualitatif. Penelitian diawali dengan mengumpulkan data berupa analisis kebutuhan.

Setelah mengetahui kebutuhan apa yang sedang dibutuhkan oleh subjek penelitian langkah selanjutnya adalah menentukan rencana pengembangan produk. Produk yang dikembangkan nantinya akan dievaluasi terlebih dahulu sebelum diuji cobakan untuk mengetahui kelemahan dan kekurangannya. Dalam uji coba lapangan awal melibatkan 12 subjek uji coba pada 1 sekolah. Setelah uji coba awal produk kembali dievaluasi dengan merevisi dan menyempurnakan hasil uji coba melalui pengamatan, wawancara dan pengisian angket. Sangat dimungkinkan memerlukan jumlah subjek uji coba yang berasal dari 5 sekolah dengan jumlah 100 subjek menggunakan teknik pengumpulan data campuran. Langkah selanjutnya adalah merevisi untuk penyempurnaan produk. Setelah produk disempurnakan selanjutnya produk tersebut dilaporkan dalam sebuah pertemuan dan dalam jurnal.

\section{HASIL DAN PEMBAHASAN}

Dari evaluasi para pakar terhadap 25 model pembelajaran kelincahan, berdasarkan hasil analisis tiap-tiap model didapatkan model pembelajaran 16 sangat sulit dilaksanakan, tetapi bisa diperbaiki yang lebih mudah dilakukan siswa sesuai dengan masukan/ saran dari para pakar penelitian.Hasil ujicoba kelompok kecil yang dilakukan terhadap 25 model pembelajaran. Berdasarkan kemudahan model pembelajaran kelincahan diperoleh nilai $85,58 \%$ dan dinyatakan baik sekali. Berdasarkan kemenarikan model pembelajaran kelincahan diperoleh nilai 86,16 dan dinyatakan 
baik sekali. Sedangkan dari ujicoba kelompok besar kemudahan model pembelajaran kelincahan diperoleh nilai 86,41 dan dinyatakan baik sekali. Berdasarkan kemenarikan model pembelajaran kelincahan diperoleh nilai 86,35 dan dinyatakan baik sekali.

\section{Keefektifan model yang} dikembangkan, dinyatakan efektif untuk digunakan. Berdasarkan dari hasil perbandingan antara nilai tes awal dan tes akhir yang diberikan kepada siswa diperoleh hasil $t_{0}$ sebesar 14,92 dan $t_{\text {tabel }}$ 1,697. Dengan demikian, $\mathrm{t}_{0}=14,92>\mathrm{t}_{\text {tabel }}=$ 1,697 atau $\mathrm{H}_{0}$ ditolak. Sehingga dapat disimpulkan terdapat perbedaan antara hasil kelincahan peserta didik setelah diberikan model pembelajaran kelincahan.

\section{KESIMPULAN}

Dalam penelitian pengembangan model, model pembelajaran Kelincahan pada siswa Taman Kanak-Kanak yang dikemas dalam buku panduan pembelajaran. Berdasarkan data yang telah dikumpulkan dari hasil penelitian yang terdiri dari validasi ahli, uji coba kelompok kecil dan uji coba kelompok besar serta pembahasan hasil penelitian, maka peneliti dapat menarik kesimpulan bahwa: 1) Pengembangan model yang diperoleh secara keseluruhan dari ahli pembelajaran pendidikan jasmani menyatakan bahwa model yang dikembangkan termasuk dalam kategori baik dan layak digunakan, 2) Pengembangan model yang diperoleh secara keseluruhan dari ahli pembelajaran gerak menyatakan bahwa model yang dikembangkan termasuk dalam kategori sangat baik dan layak digunakan. 3) Pengembangan model yang diperoleh secara keseluruhan dari ahli Tes dan Pengukuran Olahraga menyatakan bahwa model yang dikembangkan termasuk dalam kategori baik sekali dan layak digunakan Uji coba kelompok kecil dan uji coba kelompok besar dinyatakan efektif untuk digunakan. 4) Melalui pengembangan model pembelajaran kelincahan yang telah peneliti kembangkan, hasil belajar peserta didik dapat meningkat 
DAFTAR PUSTAKA

Dewis, Jay dan Mark Roozen, Developing Agility and Quickness, United States Of America: Human Kinestetik, 2012

Gall, Meridith D., Joyce P. Gall dan Walter. Borg, Educational Research An Introduction, New York: Longman, 1983.

Gatz, Greg, Complete Conditioning for Soccer, United States Of America: Human Kinestetik, 2009.

Husdarta, Model Pembelajaran Langsung Dalam Pendidikan Jasmani dan Kesehatan, Bandung: Alfabeta, 2013.

Joyce, David dan Daniel Lewindon, High-Performance Training For Sports, United States Of America: Human Kinestetik, 2014.

Lancaster, Scot dan Radu Teodorescu, Athletic Fitness For Kids, United States Of America: Human Kinestetik, 2008.

Mackenzie, Brian .101 Performance Evaluation Tests, London, 2005.

Meridith D. Gall, Joyce P. Gall dan Walter. Borg, Educational Research An Introduction, New York: Longman, 1983.
Siregar, nofi M. (2011). Kemampuan Guru TK Dalam Mengajar Gerak Anak Pada Taman Kanak-Kanak di Matraman Jakarta -Timur Dalam Upaya Peningkatan Kebugaran Jasmani Pada Anak Usia Dini, 7, 11-19.

Solso, Robert L, Ottoh. Maelun, M. Kimberly Maelin, Psikologi Kognitif, Jakarta: Erlangga, 2007

Susanto, Ahmad. Perkembangan Anak Usia Dini, Jakarta, Prenada Media Group, 2014.

Sock Miang, Teo-Koh .Fundamental Movement Skills, Singapore: Singapore Sport Council, 2012.

Tung, Khoe Yao., Pembelajaran dan Perkembangan Belajar, Jakarta: Indeks, 2015.

Tangkudung, James dan Wahyuningtyas Puspitorini.Kepelatihan Olahraga edisi II, Jakarta: Cerdas Jaya, 2012.

Trisna Rahayu, Ega., Strategi Pembelajaran Pendidikan jasmani, Bandung: Alfabeta. 2013.

Widiastuti.Tes dan Pengukuran Olahraga, Jakarta: PT. Bumi Timur Raya, 2011 